Int. J. Electrochem. Sci., 11 (2016) 2612 - 2620

\title{
Catalase Immobilized ZnO Nanorod with $\beta$-cyclodextrin Functionalization for Electrochemical Determination of Forchlorfenuron
}

\author{
Haiwei Xie ${ }^{1 *}$, Bing Wen ${ }^{1}$, Hui Xu ${ }^{1}$, Liu Liu ${ }^{2}$ and Yong Guo ${ }^{2}$ \\ ${ }^{1}$ Department of Food and Bioengineering, Bengbu University, Bengbu 233030, P. R. China \\ ${ }^{2}$ College of BioScience and Biotechnology, South China University of Technology, Guangzhou, \\ 510640, P. R. China \\ *E-mail: haiweixie_bbu@yahoo.com
}

doi: $10.20964 / 110402612$

Received: 24 January 2016 / Accepted: 18 February 2016 / Published: 1 March 2016

\begin{abstract}
In this communication, we demonstrated a forchlorfenuron (FF) electrochemical biosensor based on a catalase immobilized $\mathrm{ZnO}$ nanorod with $\beta$-cyclodextrin functionalization $(\mathrm{CA}-\beta-\mathrm{CD}-\mathrm{ZnO})$. CA was immobilized on the $\beta-\mathrm{CD}$ functionalized $\mathrm{ZnO}$ rods. The prepared $\mathrm{CA}-\beta-\mathrm{CD}-\mathrm{ZnO}$ was highly sensitive to the electrochemical reduction of $\mathrm{H}_{2} \mathrm{O}_{2}$. After introduction of $\mathrm{FF}$ into the $\mathrm{H}_{2} \mathrm{O}_{2}$ electrochemical detection system, the current change had a linear relationship with the FF concentration. Investigation showed the CA- $\beta-\mathrm{CD}-\mathrm{ZnO}$ could be used for detecting FF in the concentration range between 0.005 to $2 \mu \mathrm{M}$ with a low detection limit of $0.002 \mu \mathrm{M}$. Moreover, the CA- $\beta-C D-Z n O$ was successfully demonstrated for FF detection in fruit samples.
\end{abstract}

Keywords: Catalase; ZnO rod; $\beta$-cyclodextrin; Forchlorfenuron; Electrochemical sensor

\section{$\underline{\text { FULL TEXT }}$}

(C) 2016 The Authors. Published by ESG (www.electrochemsci.org). This article is an open access article distributed under the terms and conditions of the Creative Commons Attribution license (http://creativecommons.org/licenses/by/4.0/). 